\title{
The Application of Participatory Learning in College Mathematics Teaching
}

\author{
Miaomiao Yang1, Yu Tian², Yulin Huang ${ }^{*}$ \\ ${ }^{1}$ Division of Mathematics and Artificial Intelligence, Qilu University of Technology (Shandong Academy of Sciences), Jinan, \\ China \\ ${ }^{2}$ Department of Science and Technology Management, Shandong University, Jinan, China \\ Email: *3d07@163.com
}

How to cite this paper: Yang, M. M., Tian, Y., \& Huang, Y. L. (2022). The Application of Participatory Learning in College Mathematics Teaching. Open Journal of Social Sciences, 10, 130-136.

https://doi.org/10.4236/jss.2022.101010

Received: December 17, 2021

Accepted: January 14, 2022

Published: January 17, 2022

Copyright (c) 2022 by author(s) and Scientific Research Publishing Inc. This work is licensed under the Creative Commons Attribution International License (CC BY 4.0).

http://creativecommons.org/licenses/by/4.0/

\begin{abstract}
Taking the course Probability Theory and Mathematical Statistics as an example, this paper designs classroom participatory learning activities to change the traditional teaching-centered classroom into learning-centered classroom, effectively stimulating students' interest in learning and improving their learning efficiency.
\end{abstract}

\section{Keywords}

Participatory Learning, Probability Theory and Mathematical Statistics, Classroom Design

\section{Introduction}

Most of the common mathematics courses in colleges and universities are taught in the same classroom with several classes. Now the teachers' "full hall" teaching method is dominating the majority of college mathematics public classes. For students, the knowledge is passively accepted. This kind of class makes it difficult for students to really participate in studying and to experience the fun of learning. The lack of interaction and thinking collisions between teachers and students and among the students is not conducive to the cultivation of students' distinguishing and cooperative spirit.

It is an important part of educational innovation to design participatory learning activities in the teaching process of college mathematics common courses. It is of great significance to improve the interaction between students and teachers, and among students. It can enable students to acquire knowledge actively in the activities and strengthen the subject status of students' learning. Mathematics courses are not suitable for debate, role playing and other activities, and there 
are no operational activities such as experiments. Group discussion and other normal activities are not suitable for common large class teaching. Therefore, this paper proposes participatory learning activities suitable for mathematics courses (Peng \& Song, 2004, Chen \& Wu, 2015).

\section{Participatory Learning}

In recent years, BOPPPS teaching model has been widely successful abroad, which advocates the design of participatory learning activities in teaching (Wu, Jiang, \& Chen, 2019). The BOPPPS teaching model originated in Canada (Cao \& Yin, 2016). It breaks the classroom into: Bridge-in, Objective/Outcome, Pre-assessment, Participatory Learning, post-assessment and Summary (Niu \& Lou, 2017).

Bridge-in: Teachers can use pictures, videos, stories, questions, hot topics and other methods to start a lesson. The introduction must be lively and interesting to attract students' attention and stimulate their curiosity and interest in learning.

Objective/Outcome: Use blackboard writing, PPT and other methods to present students with specific learning objectives. Learning objectives should include three aspects: cognition, emotion and skills. Learning objectives should be set according to the analysis of learning conditions, which is clear and in line with the actual situation of students. At the same time, learning goals should be attainable and verifiable. This part is intended to allow students to clarify what goals they want to achieve in the lesson, so they can learn in a targeted manner.

Pre-assessment: Before explaining the new knowledge of this lesson, teachers can use questions and answers, quizzes, anonymous voting, group discussions and other methods to understand students' interest in this topic and prior knowledge. Then teachers can adjust the depth and progress of the subsequent teaching content to make the learning objectives and classroom topics more focused. This part is called pre-assessment.

After the main knowledge including concepts, key points, and difficulties is clarified, students can participate in learning activities in a plentiful and interesting way such as personal reports, group discussions, case studies, role playing, experiments, storytelling, and solitaire. Through participatory learning activities, students can improve their understanding of knowledge, deepen their impression of knowledge mastery and improve their interest in learning. Practice shows that the effect of student active participatory learning is far better than passive learning. Furthermore, through the design of this part, students can exercise their expression, communication and cooperation skills in activities.

Post-assessment: The purpose of post-assessment is to verify and test learning results. After the participatory learning, check the students' mastery in this lesson by answering questions, quizzes, exercises, operating demonstrations and reporting. Then teachers can check if the learning objectives are achieved and how the teaching effects are $(\mathrm{Du}, \mathrm{Fu}, \& \mathrm{Su}, 2020)$. This is called post-testing. 
Summary: Finally, teachers should make a summary of what we have learned in this lesson to strengthen students' impression. The teacher can highlight the knowledge points, emphasis, difficulty and learning objectives of this lesson. Let the students summarize first, the rest people supplement, and then the teacher emphasizes the key and difficult points. Then the effects are better. At last, teachers can extend and consolidate the effects of this lesson by assigning homework.

\section{Teaching Case Analysis}

Taking the Central Limit Theorem in Probability Theory and Mathematical Statistics as an example, we will introduce how to organize students to participate in class teaching inspired by the BOPPPS teaching model. The course is taught to sophomores majoring in science and engineering, economics and management. Students have learned advanced mathematics, but their math foundation is generally weak, and they think that math class is boring. Teachers need to carefully design teaching content to improve students' interest in exploration, and use participatory learning activities to make students take the initiative to acquire knowledge, so as to improve students' ability.

1) Lesson import: This lesson uses a video of a small ball experiment to import a new lesson

Several rows of nails are hammered into the board, all of which are equidistant from each other. When the balls fall down, they all fall to the left or right with a half probability when they hit the nails. The shape of the balls in the groove resembles a bell curve. We will notice that this curve is very similar to the density function of the normal distribution, which is often called the Gaussian curve. So is this a coincidence? Is this a real Gaussian curve?

BOPPPS teaching method believes that the engaging introduction can attract students' attention and improve their interest in learning, so the video of the ball experiment is introduced into the lesson to arouse students' curiosity. Use video to stimulate students' senses and students feel interesting while thinking about the problem.

2) New lesson learning

First of all, teachers need to interpret the central limit theorem: the central limit theorem is actually not a theorem, but a series of theorems. There are different central limit theorems under different conditions and occasions, but they all have a common idea: Under certain conditions, the limit distribution of the sum of a large number of random variables is a normal distribution.

Our lives are surrounded by a bell curve that represents a normal distribution. The size of snowflakes, the weight of bread, the life of light bulbs, people's IQ, academic performance, etc., all obey the normal distribution. This is because things in nature are not affected by a single factor but by a variety of random factors. As long as random X can be expressed as the sum of a large number of random variables, it is approximately normally distributed under certain conditions. So the reason why normal distribution is so common in our life comes 
from the central limit theorem.

The five-star teaching method believes that learning can be better promoted when the learning content is closely related to students' lives.

[Theorem 1] (Levy Theorem) Suppose that random variables $X_{1}, X_{2}, \cdots, X_{n}, \cdots$ are independent and have the same distribution. Both mathematical expectation and variance exist, $E X_{i}=\mu, D\left(X_{i}\right)=\sigma^{2}>0, i=1,2, \cdots, n$, when $n \rightarrow \infty$, the limiting distribution of their sum is normal:

$$
\lim _{n \rightarrow \infty} P\left(\frac{\sum_{i=1}^{n} X_{i}-n \mu}{\sqrt{n} \sigma} \leq z\right)=\frac{1}{\sqrt{2 \pi}} \int_{-\infty}^{z} \mathrm{e}^{-\frac{t^{2}}{2}} d t,
$$

where $z$ is any real number.

Here, we can test whether students have mastered the conditions of Levy theorem by using interactive questions in the App "rain-class".

[Question 1] Levy's central limit theorem requires random variables.

(A) Mathematical expectation exists

(B) Variance exists

(C) Follow the same distribution

(D) Mutual independence

This question is limited to 30 seconds to complete. This question asks students to think independently and answer by their own, and then they submit the answers. After submitting, teachers need to organize peer teaching according to the feedback of the answers. If the correct rate is less than $30 \%$, teachers should repeat and emphasize Levy theorem. If the accuracy rate is between $30 \%$ and $70 \%$, the peer teaching is organized and the second submission is made. If the correct rate exceeds $70 \%$, the teacher will issue the correct answer and teaching the new lesson.

According to Levy theorem, we can naturally obtain the following approximate calculation formula.

[Corollary 1] Suppose $X_{1}, X_{2}, \cdots X_{n}$ are independent and have the same distribution. $E\left(X_{i}\right)=\mu, D\left(X_{i}\right)=\sigma^{2}>0, i=1,2, \cdots, n$, when $n$ is sufficiently large,

$$
P\left(z_{1}<\frac{\sum_{i=1}^{n} X_{i}-n \mu}{\sqrt{n} \sigma}<z_{2}\right) \approx \Phi\left(z_{2}\right)-\Phi\left(z_{1}\right),
$$

where $z_{1}, z_{2}$ is any real number.

The "five-star teaching method" believes that only when learners apply new knowledge can they effectively promote learning. The following example is an application of the knowledge learned.

[Example 1] When the computer performs addition calculations, each addend is taken as the integer closest to it for calculation. Assuming that all rounding errors are mutually independent random variables, and they all obey a uniform distribution in the interval $[-0.5,0.5]$. Calculate the probability that the absolute 
value of the sum of the errors is less than 10 when 300 numbers are added.

This question can be designed to be interactive. Students can submit through the App "rain-class".

Next, teachers can guide students to think about how to modify the conditions of Levy theorem as follows: $X_{1}, X_{2}, \cdots X_{n}$, follows the same $0-1$ distribution, what changes will happen to the conclusion? After peer teaching, students are apt to draw the following conclusions.

[Theorem 2] (De Movre-Laplace Theorem) Let $Y_{n}$ be the number of times that event $A$ occurred among $\mathrm{n}$ times of independent Bernoulli's experiments, $p=P(A)(0<p<1)$, then

$$
\lim _{n \rightarrow \infty} P\left(\frac{Y_{n}-n p}{\sqrt{n p q}} \leq z\right)=\frac{1}{\sqrt{2 \pi}} \int_{-\infty}^{z} \mathrm{e}^{-\frac{t^{2}}{2}} d t,
$$

where $z$ is any real number, $p+q=1$. And when $n$ is sufficiently large.

$$
P\left(Y_{n}=k\right) \approx \frac{1}{\sqrt{2 \pi n p q}} e^{-\frac{(k-n p)^{2}}{2 n p q}}, k=0,1,2, \cdots
$$

Further more, we can naturally get the following approximate calculation formula:

[Corollary 2] Let $Y_{n}$ be the number of times that event $A$ occurred among $n$ times of independent Bernoulli's experiments, $p=P(A)(0<p<1)$, and when $n$ is sufficiently large, we have

$$
P\left(m_{1}<Y_{n}<m_{2}\right) \approx \Phi\left(\frac{m_{2}-n p}{\sqrt{n p q}}\right)-\Phi\left(\frac{m_{1}-n p}{\sqrt{n p q}}\right)
$$

where $p+q=1$.

Theorem 2 shows that the normal distribution is the limit distribution of the binomial distribution. Let's use the "rain-class" to interact to help students recall the limit distribution of the binomial distribution learned earlier:

[Question 2] We have learned that the limit distribution of the binomial distribution is ?

(A) Geometric distribution

(B) Hypergeometric distribution

(C) Poisson distribution

(D) Exponential distribution

The teachers can organize peer teaching and secondary submission according to the response. Based on this question, design the following interactive questions:

[Example 2] The probability of each shell hitting the aircraft is 0.01 . Find the probability of hitting 5 out of 500 shells.

The teachers can organize students into three large groups and uses three methods to calculate respectively. In a combined class, group teaching is difficult to carry out effectively, but divided into large groups is easy to implement. The first group uses the binomial distribution to calculate accurately, the second 
group uses the central limit theorem to estimate, and the third group uses the Poisson distribution to estimate.

After the students submitted their answers in the "Rain-Class", the teachers can organize the students to speak up, judge which limit distribution has the smallest error and analyze the reason. Students are divided into three large groups, each group will observe and think about the methods and answers of other groups, so it is easy to mobilize the enthusiasm of students to participate in the discussion.

3) Knowledge development: The teachers can introduce the history of the central limit theorem. Let students understand that the central limit theorem is obtained by countless scientists after more than 200 years of research, and every scientific achievement is hard-won.

4) Independent induction: Organize students to make a summary of this lesson. When student representative reports, other students check the missing. This link can exercise students' advanced ability of independent induction and summary.

\section{Summarize}

In this case, we adopted a group teaching method that is different from the general science and engineering courses and proposed two methods suitable for mathematics public class teaching.

One is to divide students into two or three large groups and organize them to use different methods or complete different sub-problems of the same problem. Due to the different methods of different groups, it is easy to create contradictions and conflicts, and there are not too many contradictions. The whole class focuses on two or three problems, which can effectively carry out participatory learning. The second is to organize student peer teaching. After students answer questions independently, peer teaching can be organized, and peers can persuade each other. Through the second submission of feedback, the correct rate of students' answers has been significantly improved through peer teaching. Peer teaching can also be organized in theorem derivation, induction and summary links. The students check each other's deficiencies, exchange and share, which effectively improves classroom teaching efficiency.

Through practice, the questionnaires we collected show that students report that interactive classrooms are more helpful for learning. The communication and collision between teachers and students, students and students are significantly improved compared with other public courses, which effectively improves the learning efficiency of students.

To sum up, the participatory learning activities proposed in this paper can effectively improve classroom interaction, stimulate students' active learning and independent inquiry, and provide a reference paradigm for classroom teaching innovation of college mathematics common class, which has high application and promotion value. In the future, the method of this paper can be further popularized in advanced mathematics, linear algebra and other classroom teachings. 


\section{Acknowledgements}

This work was supported by grant of No. 2020zd19, No. 2022JXTD002 and No. 2021PY01007 from Qilu University of Technology (Shandong Academy of Sciences), China.

\section{Conflicts of Interest}

The authors declare no conflicts of interest regarding the publication of this paper.

\section{References}

Cao, D., \& Yin, X. (2016). The BOPPPS Teaching Mode in Canada and Its Implications for Higher Education Reform. Research and Exploration in Laboratory, 2, 196-200.

Chen, D., \& Wu, Y. (2015). Learning Activity Design Based on “Digital Bloom”. The Chinese Journal of ICT in Education, 11, 34-37.

Du, H., Fu, C., \& Su, J. (2020). A Preliminary Study on the Establishment of Innovation and Entrepreneurship Curriculum System Based on OBE. Popular Science (Science Education), 6, 126-127.

Niu, Z., \& Lou, Z. (2017). Application of BOPPPS Teaching Mode in Adult Education Teaching Design. China Adult Education, 16, 97-99.

Peng, H., \& Song, H. (2004). Research on Participatory Learning Activities. Lanzhou Academic Journal, 1, 203-204.

Wu, C., Jiang, H., \& Chen, Y. (2019). Research and Application of BOPPPS Teaching Method in MOOC Teaching Design. Experiment Technology and Management, 36, 218-222. 